\title{
El ajuar funerario de Beatriz de Suabia: elementos para una propuesta iconográfica del simulacro de la reina en la Capilla de los Reyes de la Catedral de Sevilla
}

\author{
Laura MOLINA LÓPEZ \\ Universidad Complutense de Madrid \\ Departamento de Historia del Arte I (Medieval) \\ laura.molina.lopez@gmail.com
}

\begin{abstract}
RESUMEN
En este artículo analizaremos la relevancia que tuvo la figura de la reina Beatriz de Suabia en el proyecto alfonsí de la Capilla de los Reyes de la Catedral de Sevilla. Para ello, centraremos nuestra atención en el estudio del ajuar funerario de la reina, especialmente en su cojín, decorado con bordados que representan escenas galantes que serán relacionadas con algunas obras del entorno de Federico II, como los frescos del Palazzo Finco en Bassano del Grappa, atribuyéndoles un carácter nupcial. Aportaremos también datos históricos relacionados con el fecho del imperio que nos llevan a ubicar la realización del simulacro de Beatriz dentro del período de Alfonso X, para finalizar con una propuesta iconográfica para el simulacro de Beatriz de Suabia en la Capilla de los Reyes de la Catedral de Sevilla.
\end{abstract}

Palabras clave: Capilla de los Reyes, Beatriz de Suabia, Alfonso X, Fadrique, Federico II, Imperio, simulacro.

\section{The Grave Goods of Beatriz of Swabia: Elements for an Iconographical Proposal About the Queen's Simulacrum in the Royal Chapel of the Cathedral of Seville}

\begin{abstract}
This article will analyze the importance of the personality of the Queen Beatrice of Swabia in the project of the Royal Chapel inside Seville's Cathedral. For this reason, we will focus in the study of Queen's grave goods, primarily her pillow, embroidered with secular scenes well connected with many productions of Frederick II and his circle, as the fresco painting of the Palazzo Finco in Bassano del Grappa, assuming a nuptial function. We will also provide historical accounts related to the fecho del imperio that help us to date the simulacrum or statue of Beatrice inside the artistic production of Alfonso X. Finally we will make an iconographic proposal for the statue or Beatrice of Swabia in the Royal Chapel inside Seville's Cathedral.
\end{abstract}

Key words: Royal Chapel, Beatrice of Swabia, Alfonso X, Fadrique, Frederick II, Empire, simulacrum. 


\section{Introducción: el enlace de Fernando III y Beatriz de Suabia}

Fue doña Berenguela quien se preocupó por el establecimiento del enlace de su hijo Fernando III con Beatriz de Suabia ${ }^{1}$, hija de Felipe de $S a^{2} i^{2}$ y la princesa bizantina Irene (hija del emperador bizantino Isaac Angelo), abriéndose con esta unión nuevos horizontes europeos para los miembros de la Corona de Castilla ${ }^{3}$.

Las crónicas alemanas recogen la noticia de la entrega en matrimonio de Beatriz de Suabia al rey de Castilla ${ }^{4}$, pero no ofrecen datos sobre la celebración del enlace. En el caso de las crónicas castellanas, podremos hallar información en el Chronicon Mundi de Lucas de Tuy, la Cronica Latina Regum Castellae de autor anónimo (atribuida al obispo Juan de Osma) y la Historia de rebus Hispaniae del arzobispo de Toledo Rodrigo Ximénez de Rada.

Con la finalidad de formalizar dicho matrimonio, fue enviada en el año 1219 una embajada de Castilla a Alemania, encabezada por el obispo de Burgos don Mauricio $^{5}$, para la tramitación de los detalles del enlace con Federico II, primo hermano de Beatriz de Suabia. Parece ser que los embajadores permanecieron en la corte de Federico II un total de cuatro meses, lo que ha llevado a pensar en la posibilidad de que el emperador no hubiera tenido anteriormente noticias sobre el enlace. Sin embargo otras crónicas relatan que Berenguela ya había establecido contacto diplomático con Federico II ${ }^{6}$.

1 La elección de doña Beatriz de Suabia responde a su doble ascendencia imperial, pero también está relacionada con la búsqueda de la legitimidad del enlace. Este énfasis en la legitimidad se debe a que el matrimonio de Berenguela de Castilla y Alfonso IX de León, celebrado en el año 1197, fue anulado por el papa Inocencio III en el año 1204 por el parentesco cercano existente entre ambos, considerándose a sus descendientes ilegítimos. Vid. D. COLMENERO LÓPEZ, "La boda entre Fernando III el Santo y Beatriz de Suabia: motivos y perspectivas de una alianza matrimonial entre la Corona de Castilla y los Staufer", Miscelánea Medieval Murciana, XXXIV (2010), p. 14.

2 Felipe de Suabia era tío de Federico II. Recibió el encargo del emperador Enrique VI, su hermano, de desplazarse a Spoleto, donde había sido dejado bajo la protección de la duquesa el heredero Federico, de apenas tres años de edad. Ya en la Dieta de Frankfurt (1196) el emperador había nombrado a Federico rex romanorum, es decir, rey de Alemania. Sin embargo, debido a su corta edad, correspondería a Felipe de Suabia el desempeñar las labores de regente del Reino de Alemania, así como las de tutor de Federico II (F. RENDA, Federico II e la Sicilia, Catanzaro, 2012, pp. 23 y ss.).

3 D. COLMENERO LÓPEZ, op. cit. (2010), p. 10. Continúa el autor afirmando que, gracias a este enlace, Alfonso X fue considerado heredero legítimo de los Staufen y en el año 1246 reclamó su herencia materna, llegando a ser nombrado Rey de Romanos en 1257.

4 Ibid., p. 11, nota 11. Nos ofrece una recopilación de las noticias transmitidas por distintos anales alemanes sobre la entrega en matrimonio de Beatriz al rey Fernando III: "Filia regis Philippi tradita fuit nuptui regi Hyspanie et traducta", Annales Spirenses, G.H. PERTZ (ed.), MGH SS, 17, Hannover, 1861, p. 85; "Philippus rex habuit quattuor filias, quarum unam duxit rex Castelle sive Hyspanie, alteram rex Boemie, terciam Otto rex Romanorum, quartam (...)", Auctarium Vindobonense, G.H. PERTZ, (ed.), MGH SS, 6, Hannover, 1851, p. 723; "Habuit enim Phylippus filiam regis Constantinopolitani in coniugio (...) et ex ea IIII filias progenuit, que postea nupserunt, videlicet Ottoni postea imperatori et regi Hyspanie et regi Boemie atque duci Brabantie (...)", Annales Marbacenses qui dicuntur Cronica Hohenburgensis, H. BLOCH (ed.), MGH SS rer. Germ [9], Hannover-Leipzig, 1907, p. 77.

5 D. COLMENERO LÓPEZ, op. cit. (2010), p. 16, nota 36.

6 Ibid., p. 17. 
Algunos autores, como González y Socarrás, siguiendo lo recogido en la Chronica Latina $^{7}$, defienden la posible existencia de una embajada precedente en el año 1218, mientras que otros, como Meyer, son completamente contrarios a esta hipótesis ${ }^{8}$. A la copiosa información que nos ofrece Colmenero López ${ }^{9}$, queremos añadir algunos datos que podrían ser de utilidad para la valoración positiva de la controvertida embajada del año 1218. Por una lado, el cronista de Federico II, Ryccardi de Sancto Germano, nos dice que en el año 1218 la reina Constanza de Aragón ${ }^{10}$, esposa de Federico II, se desplaza a Alemania ${ }^{11}$, pudiera ser que con la finalidad de recibir a la embajada. Por otro lado, Diago Hernando justifica la permanencia de los embajadores castellanos durante un período de cuatro meses en la corte del emperador por encontrarse doña Beatriz fuera de la corte ${ }^{12}$. Aportamos a este respecto otro dato, y es que entre el año 1218 y 1219 Federico II hizo transferir los restos de Felipe de Suabia, padre de doña Beatriz, de Bamberg a Spira ${ }^{13}$, motivo por el cual pudiera haberse ausentado de la corte imperial la futura esposa de Fernando III de Castilla.

El matrimonio entre Fernando III y Beatriz de Suabia fue celebrado el día 30 de noviembre de $1219^{14}$, teniendo antes lugar una curia, precisamente con motivo de los desposorios, a la que es probable que asistieran los embajadores del imperio que habrían acompañado a doña Beatriz a Castilla ${ }^{15}$.

La unión de Fernando y Beatriz benefició tanto al monarca castellano como al emperador Federico II a nivel diplomático, además de servir para el establecimiento

7 "Post alio ergo nuncios, quos domina regina premiserat in partes Alemanie pro facto isto, receptis litteris regis Alemanie, futuri imperatoris Romanorum, de mittendis nunciis solempnioribus pro adducenda domicella, misit (...)". Tomado de D. COLMENERO LÓPEZ, op. cit. (2010), p. 17.

8 Para sostener su teoría, Meyer sigue lo recogido en la Primera Crónica General, correspondiente ya al período de Alfonso X: "et fueron a don Fredric rey de los romanos, en cuya guarda estaua entonçes la donzella donna Beatriç en Alemanna, et alli fueron estos mandaderos por ella; et rrecibiolos esse rey muy onrradamientre. Et pues que se razonaron et departieron en muchas buenas razones daca de la tierra, et al cabo mostraron la razon, assi como les fue mandado, por que eran alli venidos. El sobredicho rey et sus prinçipes ouieron su fabla sobrello, et detouieronles la respuesta por algunos dias, et los mandaderos esperaronla; et los dias de la respuesta fueron bien quatro meses, de como cuenta la estoria", R. MENÉNDEZ PIDAL (ed.), cap. 1034, p. 718. Tomado de D. COLMENERO LÓPEZ, op. cit. (2010), p. 17.

9 Ibid., pp. 9-22.

10 La princesa aragonesa, hermana de Pedro II de Aragón, contrajo nupcias con Federico II en el año 1209: "Fredericus rex Sicilie uxorem duxit Constantiam sororem regis Arragonum" (RYCCARDI DE SANCTO GERMANO, Chronica, L.A. MURATORI (ed.), Rerum Italicorum Scriptores, vol. VII, parte 2, Bolonia, 1938, p. 28). En el año 1222 murió en Sicilia: "Imperatrix in Sicilia obiit" (ibid., p. 101).

11 Ibid., p. 81. Sin embargo, el cronista no recoge ninguna información sobre una embajada en la corte del emperador, ni en el año 1218 ni el 1219, y no hace ninguna mención a la entrega en matrimonio de su prima Beatriz a Fernando III.

12 M. DIAGO HERNANDO, "La monarquía castellana y los Staufer. Contactos políticos y diplomáticos en los siglos XII y XIII”, Espacio, Tiempo y Forma. Serie III. Historia Medieval, 8 (1995), pp. 64-66.

13 F. VERGARA CAFFARELLI, "Fonti documentarie per la storia delle tombe reali", M. ANDALORO, et al. (coords.), Il sarcofago dell'Imperatore. Studi, ricerche e indagini sulla tomba di Federico II nella Cattedrale di Palermo. 1994-1999, Palermo, 2002, p. 318.

14 D. COLMENERO LÓPEZ, op. cit. (2010), p. 9.

15 RODRIGO XIMÉNEZ DE RADA, Historia de rebus Hispaniae, libro 9, capítulo 10, relata cómo Beatriz fue enviada a Castilla “cum apparatu nobili”. Tomado de D. COLMENERO LÓPEZ, op. cit. (2010), p. 12 , nota 18 . 
de una sólida amistad entre ellos ${ }^{16}$. Fernando había contraído matrimonio con una heredera imperial por partida doble, mientras que Federico II se podría aprovechar de las buenas relaciones de Fernando III con el Papado para ser coronado emperador ${ }^{17}$.

Este matrimonio de Fernando III con Beatriz de Suabia trajo consigo el planteamiento del problema de la herencia de la reina. Hasta ahora no se ha podido determinar con claridad cuáles eran los territorios y privilegios que configuraban dicha herencia; aunque es probable que, tras la negociación del matrimonio, Federico II hubiera prometido a su prima Beatriz ciertos bienes, siendo estos los que la reina querría legar a su hijo Fadrique.

El papel que jugó la figura de la reina doña Beatriz en la política castellana gozó de enorme importancia, quizá en especial modo después de su fallecimiento en 1235, convirtiéndose en el argumento principal para la defensa que Alfonso X realizará a lo largo de toda su vida de su derecho legítimo a la herencia imperial tras la muerte de Federico II, en 1250, y la de Conrado IV, en el año $1254^{18}$. Nos referimos al conocido como fecho del imperio, asunto que ocupará gran parte de la política exterior del rey sabio y en cuya órbita debemos ubicar también el proyecto de la Capilla de los Reyes, como veremos más adelante.

Este proyecto imperial alfonsí cobrará vida con la llegada a Soria de unas embajadas procedentes de Pisa en el mes de marzo de 1256, encabezadas por Bandino Lancia, quien, en su discurso de ofrecimiento de la herencia imperial a Alfonso X,

16 Prueba de ello son las líneas que Federico II dedicó a Fernando III poco antes de su muerte en una carta: "Pensantes amoris affectum, quem ad vos semper habuimus hactenus (...)", J.L.A. HOUILLARDBREHOLLES (ed.), Historia Diplomatica Frederici Secundi sive Constitutiones, Privilegia, Mandata, Instrumenta quae supersunt istius imperatoris et filiorum ejus, vol. VI, 2, París, 1861, p. 769.Tomado de D. COLMENERO LÓPEZ, op. cit. (2010), p. 11, nota 9.

17 Quizá precisamente por estas favorables relaciones del rey de Castilla con el Papado, el cronista Ryccardi de Sancto Germano pone tanto énfasis en plasmar en su Chronica los logros de los reinos hispánicos en el proceso de la Reconquista. Se recoge pues, la noticia de la victoria cristiana en la Batalla de las Navas de Tolosa (1212): "Hoc anno christiani principes, uidelicet rex Castelle, rex Navarrae et rex Arragonum cum Miramammolino Sarracenorum principe prelium ineuntes, Dei fauente uirtute, contra eum optinuerunt. Quod ad omnium orientalium gaudium et exultationem; idem rex Castelle de tanta christianis principus celitus concessa victoria dicto Innocentio pape litteras mittit. Mitit etiam de acceptis Sarracenorum spoliis eidem honorabilia exenia, tentiorum contextum. Quod in principis apostolorum basilica in laudem nominis Christi appensum est", reproduciendo después el texto de una carta de Alfonso VII dirigida al Pontífice Inocencio IV (RYCCARDI DE SANCTO GERMANO, op. cit., 1938, pp. 35 y ss.). Del mismo modo nos relata cómo el rey Fernando III promueve la guerra contra los enemigos de la religión católica, empresa que gozaba del beneplácito del papa Honorio III: "Reges Hyspani terram M[iramammo]lini intrant" (ibid., p. 123). También encontramos en esta Chronica una reseña de la conquista de Córdoba (1236): "Mense Iunii in uigilia apostolorum Petri et Pauli capta est Corduba, nobilissima Saracenorum ciuitas, qua preter Romam Constantinopolim et Hispalym nulla maior in orbe dicitur a Ferrando cristianissimo rege Toleti et Castelle. Corduba uicta iaces, te uicit ut Deo uaces, Uictor Ferrandus, Hyspanie rex memorandus" (ibid., p. 191).

18 Conrado IV aparece representado en la Cantiga CXXXVI del Códice Rico de El Escorial (Ms. T-I-1, Real Biblioteca del Monasterio de San Lorenzo de El Escorial, fols. 191v.-192r.), ambientada en la ciudad de Foggia. En el texto se afirma "En essa vila segund' eu aprix en verdade, / fillo do Emperador, i era rei Corrade". Vid. L. MOLINA LÓPEZ, "Viaje a Italia a través de las Cantigas Historiadas de Alfonso X el Sabio", G. DEL VAL MORENO y S. FUENTES LÁZARO (eds.), Saberes artísticos bajo signo y designios del Urbinate, vol. extraordinario de Anales de Historia del Arte, noviembre (2011), pp. 325 y ss., y "El valor de la ciudad como fuente documental en las Cantigas Historiadas de Alfonso X el Sabio: el caso de Foggia", Ángulo Recto: Revista de estudios sobre la ciudad como espacio plural, 3/1 (2011), pp. 53-62. 
apelará a la vinculación del monarca con la casa de Suabia, utilizando las siguientes palabras:

"natum de progenie domus ducum Suevie ad quam de privilegio principum et de concessione romane ecclesie pontificum imperium uiste et digne dignoscitur pertinere" 19.

\section{La Capilla de los Reyes de Sevilla: contexto y modelos}

En este proceso de reclamación del imperio por parte de Alfonso X, jugará un importante papel la Capilla de los Reyes de la Catedral de Sevilla, que debe ser interpretada no solo como espacio funerario en conmemoración de los reyes, sino como un escenario triunfal de la monarquía castellano-leonesa ${ }^{20}$. Sin embargo, no debemos olvidar que esta capilla fue también concebida por Alfonso X como vehículo de exaltación de su propia figura, sea como heredero del Reino de Castilla y León, sea como legítimo sucesor de la dinastía Staufen a través de la figura de su madre. Los trabajos de realización de esta capilla debieron iniciarse entre los años 1261 y $1268^{21}$, encontrándose en un estado muy avanzado en noviembre de $1271^{22}$.

La configuración espacial de la capilla la conocemos gracias a un sello medieval (Fig. 1) que nos muestra la disposición original de los elementos ${ }^{23}$. Así, el espacio representado en este sello se encontraba presidido por la escultura de la Virgen de los Reyes, conservada en la actual Capilla de los Reyes de la Catedral de Sevilla. Por debajo de esta imagen se encontrarían otras tres esculturas, denominadas simulacros,

19 P. TRONCI, "Memorie Istoriche della Città di Pisa", Historiae Urbium et Regionum Italiae Rariores, n. XLIII, Bolonia, 1967 (Ristampa foto meccanica; originale dell'anno MDCLXXXII), pp. 202 y ss. El documento original se encuentra en el Archivio di Stato di Pisa: 1256 marzo 18 ind. XIV, Soria di Spagna. Los pisanos no fueron los únicos en hacer mención al linaje de Alfonso X en relación con la disputa por la corona imperial. En el año 1260 se produce otra embajada, esta vez desde Florencia, encabezada por Brunetto Latini, maestro de Dante Alighieri. Fue precisamente el embajador quien recogió los hechos del siguiente modo: “[...] esso comune saggio [Florencia] / mi fece suo mesaggio / all'alto re di Spagna, / ch'or è de la Magna / e la corona atende / se Dio no.llil contende: / che già sotto la luna / non si truova persona / che, per gentil legnaggio / né per altro barnaggio / tanto degno ne fosse / com'esto re Nanfosse. / E io presi campagna / e andai in Ispagna / e feci l'ambasciata / che mi fu ordinata[...]" (B. LATINI, Il Tesoretto, Milán, 1985, pp. 4 y ss.). Para la puesta en relación de esta última embajada con la producción artística alfonsí vid. L. MOLINA LÓPEZ, op. cit. (2011), pp. 321 y ss.

20 L. FERNÁNDEZ FERNÁNDEZ, “'Muy noble, et mucho alto et mucho honrado'. La construcción de la imagen de Fernando III", C. DE AYALA y M. RÍOS SALOMA (eds.), Fernando III. Tiempo de cruzada, Madrid, 2012, pp. 143-144.

21 Recientemente, Juan Carlos Ruiz Souza ha puesto en relación la concepción de la Capilla de los Reyes de Sevilla con la promulgación de la Bula Transiturus por el Papa Urbano IV en el año 1264, conocida como la elevación del cuerpo de Cristo, eligiendo este momento el rey sabio para configurar una Capilla Real con los sepulcros en alto: J.C. RUIZ SOUZA, “Alfonso X y el triunfo de la visualización del poder", Alcanate, VIII (2012-2013), pp. 233 y ss.

22 T. LAGUNA PAÚL, "Devociones reales e imagen pública en Sevilla", P. MARTÍNEZ TABOADA, E. PAULINO MONTERO y J.C. RUIZ SOUZA (eds.), Palacio y Génesis del Estado Moderno en los reinos hispanos, $\mathrm{n}^{\circ}$ especial (II) de Anales de Historia del Arte, 23 (2013), p. 147.

23 Vid. M.J. SANZ SERRANO, "Imagen del antiguo tabernáculo de plata, de la Capilla Real de Sevilla, a través de dos sellos medievales", Laboratorio de Arte, 11 (1998), pp. 51-68. 
que no eran otra cosa que las representaciones de los difuntos (Fernando III, Alfonso $\mathrm{X}$ y Beatriz de Suabia) en posición sedente bajo baldaquino, o lo que es lo mismo "en silla" 24 . Finalmente, y correspondiéndose con cada una de estas esculturas, se encontrarían los sepulcros.

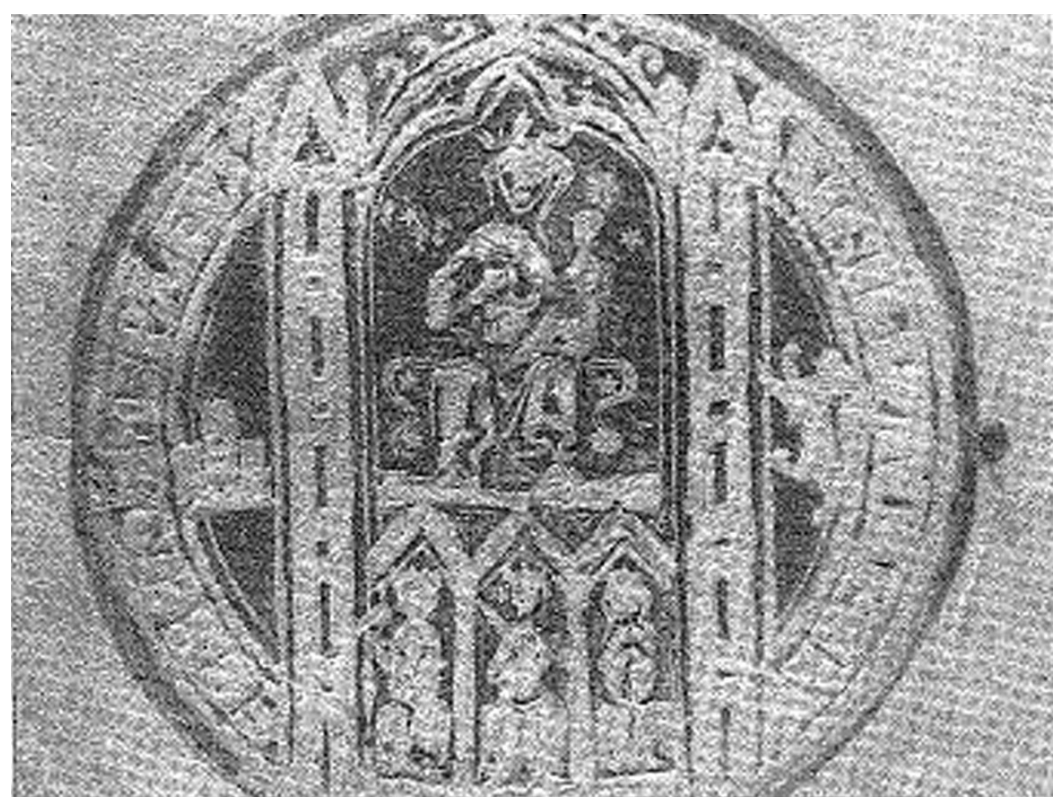

Fig. 1. Sello de la Capilla de los Reyes de Sevilla, finales del s. XIII o primera mitad del s. XIV [M.J. SANZ, op. cit., 2000, p. 442].

Son numerosos los elementos que ligan a esta empresa alfonsí con importantes producciones de la órbita de Federico II. En primer lugar, la ubicación de la capilla funeraria en las inmediaciones del altar mayor ${ }^{25}$, en un formato ajeno a la tradición castellana, tal y como sucedía en el "Cimitero dei Re" de la Catedral de Palermo, donde reposan los restos de Federico II, Constanza de Aragón, Enrico VI, Costanza d'Altavilla y Ruggero II. En segundo lugar, podemos aludir a la carencia de esculturas yacentes en los sarcófagos ${ }^{26}$, optando por la representación de los difuntos a

24 J.C. RUIZ SOUZA, op. cit. (2013), p. 239.

25 Como afirma Juan Carlos Ruiz Souza, "por primera vez asistimos a la privatización de un presbiterio catedralicio" (ibid.). Se produce en estos años también la reorganización del Panteón Real del Monasterio de las Huelgas de Burgos, finalizada en el año 1279, con la realización de sepulturas para Alfonso VIII y Leonor Plantagenêt en la zona del coro. En este mismo año se produce el traslado del cuerpo de Beatriz de Suabia (vid. T. LAGUNA PAÚL, "La capilla de los Reyes de la Primitiva Catedral de Santa María de Sevilla y las Relaciones de la Corona Castellana en el Cabildo Hispalense en su Etapa Fundacional", Maravillas de la España Medieval, Valladolid, vol. 2, 2001, p. 240).

26 Con respecto a este asunto, destacamos J. MARTÍNEZ DE AGUIRRE, "La primera escultura gótica en Sevilla: la Capilla Real y el sepulcro de Guzmán el Bueno (1248-1320)", Archivo Español de Arte, LXVIII, 270 (1995), pp. 111-129. 
través de los simulacros ${ }^{27}$, que proyectan una imagen viviente de los reyes cuyos restos allí reposan.
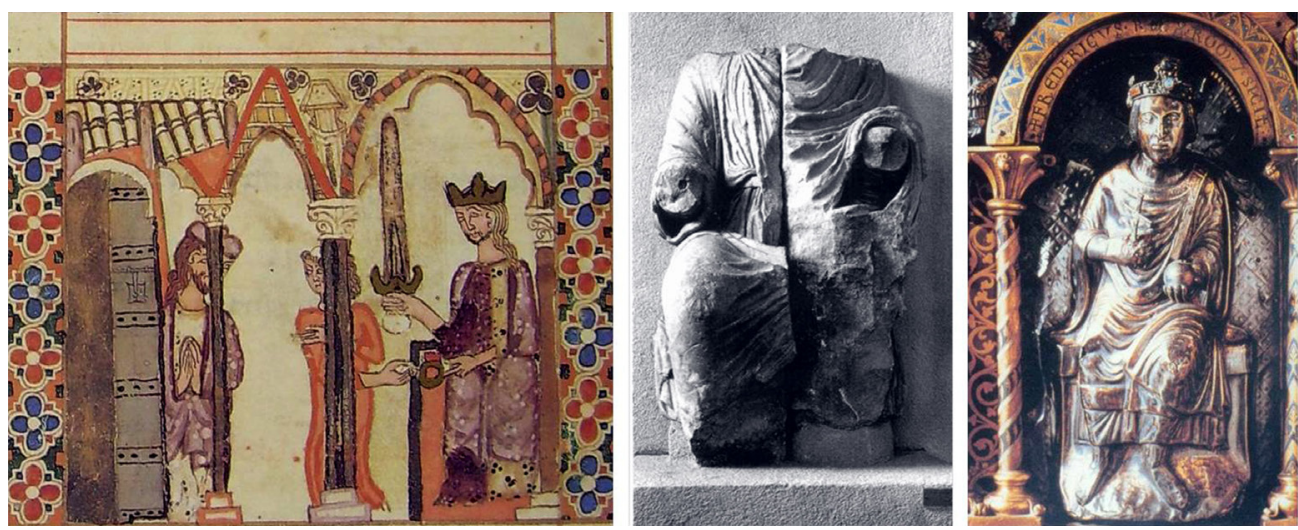

Fig. 2. a) Representación del simulacro de Fernando III. Cantigas de Santa María, c. 1282-1284 (Florencia, Biblioteca Nazionale Centrale, ms. B.R.20, f. 12r.) (detalle); b) Escultura acéfala de Federico II en la Porta di Capua, c. 1239 [P.C. CLAUSSEN, "Creazione e distruzione dell'immagine di Federico II nella Storia dell'Arte. Che cosa rimane?", M.S. CALÒ MARIANI y R. CASSANO (coords.), op. cit., 1995, p. 78]; c) Efigie de Federico II en el arca relicario de Carlomagno, c. 1215 [M. ANDALORO, op. cit., 2002, p. 135].

El caso de los simulacros será tratado con mayor atención, ya que es parte crucial de este estudio. Desafortunadamente, las representaciones esculpidas de los monarcas en majestad se han perdido. Solamente tenemos conocimiento de ellas a través de fuentes documentales, pudiendo añadir, en el caso de Fernando III, una representación gráfica en el Códice de Florencia de las Cantigas de Santa María ${ }^{28}$ (Fig. 2a). Esta tipología de representación del monarca difunto es atípica dentro de la tradición escultórica castellana ${ }^{29}$. Como modelos para este tipo de esculturas sedentes con valor funerario se han propuesto relaciones con el cuerpo incorrupto de Carlomagno hallado en Aquisgrán en torno al año mil ${ }^{30}$, la escultura de Carlos I d'Anjou realizada por Arnolfo di Cambio hacia $1277^{31}$, la escultura sedente de Federico II en la Porta Romana de Capua (Fig. 2b), o el cuerpo embalsamado del Cid entronizado en el Monasterio de San Pedro de Cardeña ${ }^{32}$. Con respecto a este último, Laura Fernández

27 En nuestra opinión, se enmarcarían en el período del reinado de Alfonso X los simulacros de Fernando III y doña Beatriz.

28 Cantiga 292, Códice de Florencia (Florencia, Biblioteca Nazionale Centrale, Ms. B.r.20, fol.12 r.).

29 J. MARTÍNEZ DE AGUIRRE, "La introducción de la escultura gótica en Sevilla (1248-1300)", Metropolis Totius Hispaniae, Sevilla, 1998, p. 126.

30 J. MARTÍNEZ DE AGUIRRE, op. cit. (1995), p. 121.

31 Ibid.

32 R. SÁNCHEZ AMEIJEIRAS, "La fortuna sevillana del Códice Florentino de las Cantigas: tumbas, textos e imágenes", Quintana, 1 (2002), pp. 259-276; R. ALONSO ÁLVAREZ, "De Carlomagno al Cid: la memoria de Fernando III en la Capilla Real de Sevilla", J.M. NIETO SORIA (coord.), Fernando III y su tiempo, Ávila, 2003, pp. 469-488. 
destaca que la visita de Alfonso X al Monasterio de Cardeña en el año 1272, y el consiguiente conocimiento de la leyenda del Cid, podrían haber servido de referente para la ubicación del simulacro de Fernando III en la capilla, pudiendo ser tomada esta fecha como post quem para la realización tanto de la capilla como del simulacro ${ }^{33}$.

Por nuestra parte, consideramos que se pueden añadir otros ejemplos a esta lista de modelos para las esculturas sedentes con función funeraria. En primer lugar, proponemos la conexión con la efigie del propio Federico II en el arca relicario de Carlomagno, representado en trono y con los símbolos de poder (Fig. 2c). En esta arca relicario fueron depositados los restos de Carlomagno el día 27 de julio de $1215^{34}$, siendo cerrada después por el propio Federico $\mathrm{II}^{35}$. Del mismo modo, consideramos oportuno destacar cómo en el ámbito normando-suabo era una tradición muy difundida la de representar a los monarcas en majestad en los lugares donde estaba prevista, al menos en principio, su sepultura. Como testimonios de esta tradición mencionaremos las pinturas perdidas de la Porta Regum de la Catedral de Cefalù ${ }^{36}$, descritas en un documento del año 1329 denominado Rollus Rubeus, con la representación de Ruggero II, Guglielmo I, Guglielmo II, Costanza d'Atavilla y Federico II, este último sentado en trono; y la representación, también perdida, de Manfredi en majestad rodeado de águilas suabas en la Catedral de Messina ${ }^{37}$.

Como es sabido, Alfonso X nunca llegó a realizar su ansiada ida al Imperio, por lo que cabe preguntarse cómo pudo tener conocimiento de los modelos enumerados más arriba. Sin salir de su círculo familiar, podemos destacar dos figuras que pudieron informar al monarca sobre las mencionadas empresas artísticas que se estaban llevando a cabo en el entorno del imperio: doña Beatriz y don Fadrique.

La reina Beatriz de Suabia debió conocer muy bien y con detalle la leyenda del hallazgo de Carlomagno y el traslado de sus restos, en primera instancia por Federico I Barbarroja a un arca de madera, y posteriormente por Federico II a un arca relicario de elevada riqueza. Es altamente probable, además, que Beatriz asistiera a la ceremonia del cierre del arca relicario protagonizada por Federico II el 27 de julio de $1215^{38}$.

De gran interés, y mayor proximidad cronológica, resulta la posible aportación de don Fadrique, hermano menor de Alfonso X que sí realizó su ida al Imperio entre los

33 L. FERNÁNDEZ FERNÁNDEZ, op. cit., 2012, p. 149

34 Anteriormente los restos de Carlomagno habían sido introducidos en un arca de madera por Federico I Barbarroja, abuelo de Federico II.

35 M. ANDALORO, "Per la conoscenza e la conservazione delle tombe reali della Cattedrale di Palermo", M. ANDALORO et al. (coords.), op. cit., 2002, pp. 135 y ss. Reproduce la autora en la nota 7 de este estudio cómo se produjo este episodio: "Feria secunda missa sollemniter celebrata, idem rex corpus beati Carlomanni. quod avus suus Fredericus imperator de terra levaverat, in sarcofagum nobilissimum, quod Aquenses fecerant, auro argento contextum reponi fecit, et accepto martello, depositoque pallio, cum artefice machinam ascendit, et videntibus cunctis cum magistro clavos infixos casi firmiter clausit".

36 Vid. M.-J. JOHNSON, "The Lost Royal Portraits of Gerace and Cefalù Cathedrals", Dumbarton Oaks Papers, 53 (1999), pp. 237-259.

37 Esta representación existía ya en el año 1282, cuando Pedro de Aragón visitó la Catedral de Messina. A principios del s. XX salieron a la luz en la techumbre restos de los escudos tanto suabos como angevinos. Vid. A. SALINAS, "Un palinsesto araldico svevo-angioino nel Duomo di Messina", Bollettino d'Arte, V/1 (1911), pp. 89-92.

38 No olvidemos que, tras la muerte de Felipe de Suabia, Beatriz quedó bajo la custodia de su primo hermano Federico II hasta la fecha en la que fue dada en matrimonio a Fernando III de Castilla. 
años 1240 y $1245^{39}$, ya que en principio era a él a quien correspondería la herencia materna del ducado de Suabia. Durante este período no hay constancia documental de su estancia en Palermo. Sin embargo, años después, en 1266, Fadrique volverá a Italia, en concreto a Sicilia, recibiendo un sueldo de 100 piezas de oro de parte de Manfredi ${ }^{40}$, hijo bastardo de Federico II que había asumido el poder tras la muerte de Conrado IV en el año 1254. El regreso del infante al Reino de Castilla se debió producir a finales del año 1271, apareciendo de nuevo en la documentación diplomática castellana en el mes de enero de $1272^{41}$. Quizá Fadrique pudo dar noticias a su hermano sobre las empresas artísticas anteriormente mencionadas. Además, debemos recordar que es en aquel mismo año en el que Alfonso X visita el Monasterio de San Pedro de Cardeña y en el que comienza a promover la actualización de algunos espacios funerarios asociados a la corona castellana, desplazando los sepulcros a la zona del altar mayor ${ }^{42}$.

Aún podemos añadir algunos datos históricos más que podrían ayudar a ubicar el proyecto de la Capilla de los Reyes como lugar de reposo de Fernando III y Beatriz de Suabia, al menos desde un punto de vista conceptual, en los primeros años de la década de 1270, más concretamente entre los años 1271 y 1274. En el año 1271 Alfonso X es reconocido emperador por el común de Milán ${ }^{43}$, pero sin contar con el reconocimiento del pontífice Gregorio X. Por ello en el año 1272 el rey sabio solicita su coronación como Rey de Romanos, petición ante la cual el Papa no se muestra muy favorable. Alfonso X insiste en entrevistarse con Gregorio X, hasta que en el mes de noviembre de 1273 este accede a entrevistarse con el monarca ${ }^{44}$. Como podemos imaginar, en este último resquicio de reclamación de sus derechos imperiales, la importancia de la figura de Beatriz volvería a resurgir, convirtiéndose de nuevo en la piedra angular de la candidatura del rey sabio, lo que justificaría el deseo de trasladar el cuerpo de la reina desde el Monasterio de las Huelgas de Burgos para la configuración, junto con Fernando III, de una escenografía de representación del poder adecuada a las aspiraciones imperiales del ya rey de Castilla y León.

\section{El ajuar funerario de Beatriz de Suabia}

Hasta ahora, ha sido bastante escasa la atención que se ha prestado a la figura de la reina dentro del contexto de la Capilla de los Reyes. De este modo, pocas y parcas

39 Vid. L. MOLINA LÓPEZ, "La entrada de un modelo arquitectónico federiciano en el Reino de Castilla: la Torre de don Fadrique”, F.A. GARCÍA GARCÍA, I. GONZÁLEZ HERNANDO y E. PAULINO MONTERO (eds.), Nuevas investigaciones en Historia del Arte, vol. extraordinario de Anales de Historia del Arte, octubre (2010), pp. 185-200.

40 M. GONZÁLEZ JIMÉNEZ, Alfonso X el Sabio, Barcelona, 2004, p. 232, nota 69.

41 Ibid., pp. 232-233.

42 Vid. nota 25.

43 M. GONZÁLEZ JIMÉNEZ, op. cit., 2004, p. 233.

44 Estas entrevistas son la conocidas como entrevistas de Beaucaire, y tuvieron lugar entre los meses de mayo y agosto de 1275. En estos encuentros, Gregorio X instó a Alfonso X a desistir de su empresa imperial y a dejar de utilizar en su documentación oficial el título de Rey de Romanos, aunque el rey sabio continuará usando este epíteto hasta el año 1282 (ibid., pp. 280-286). 
son las descripciones que nos han llegado sobre su ajuar, ya que los cronistas han puesto mayor interés en aquellos pertenecientes a Alfonso X y, en particular modo, a Fernando III.
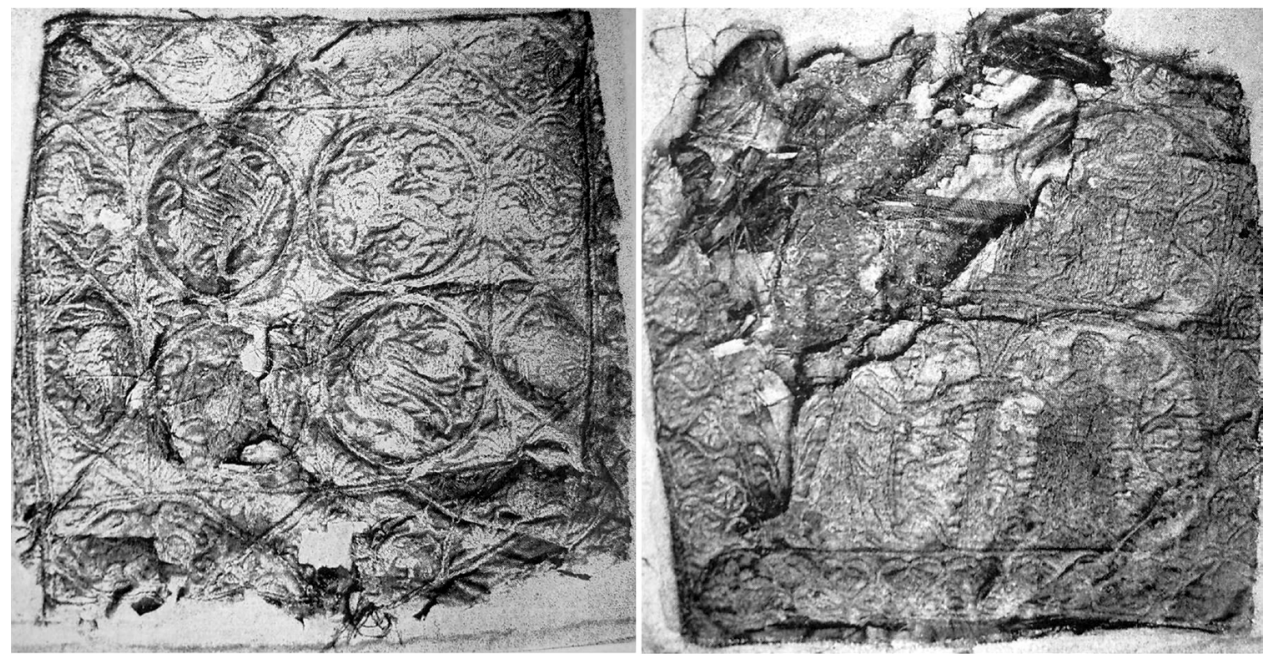

Fig. 3. Reverso y anverso del cojín de Beatriz de Suabia, Capilla de los Reyes, Catedral de Sevilla [M. GÓMEZ MORENO, op. cit., 1948].

En las aperturas que se llevaron a cabo en los años $1579^{45}$ y $1677^{46}$, la información que se nos ofrece sobre el ajuar hallado en el sarcófago de Beatriz alude a la existencia de una pulsera de cuentas sobre trencilla negra, añadiendo en el último de los casos el hallazgo de unos guantes de seda morada y oro muy deteriorados.

Parece ser que tras esta apertura, el sarcófago de doña Beatriz permaneció cerrado hasta el año 1948 cuando, con motivo del séptimo centenario de la conquista de la ciudad, fue abierto de nuevo. En este caso, el encargado de la realización del estudio de los ajuares funerarios fue Manuel Gómez Moreno ${ }^{47}$, realizándose también una

45 En este año se produce el traslado de los cuerpos a la nueva Capilla Real: M.J. SANZ, “Ajuares funerarios de Fernando III, Beatriz de Suabia y Alfonso X”, M. GONZÁLEZ JIMÉNEZ (coord.), Sevilla 1248, Madrid, 2000 , p. 420. En el caso del sarcófago de doña Beatriz, Morgado relata que "iba cubierto de brocado carmesí hasta el suelo, y armas bordadas de oro a las esquinas, con flueco y guarnición de oro", mientras que sobre el interior afirma que "tenía una muñeca con una manilla de un Tegillo negro con aljófar a la redonda". Años más tarde, Ortiz de Zúñiga, utilizando como base el acta de apertura de 1579, nos ofrece nuevos datos, relatando cómo la caja de la reina Beatriz se encuentra "cubierta de tela de oro y chapada de castillos y leones de plata, y clavazón dorada con sus aldabas y tachuelas doradas" (ibid., p. 422).

46 En este año Carlos II ordenó que el sarcófago de doña Beatriz y el de Alfonso X fueran ubicados en los nichos laterales en los que se encuentran en la actualidad, ya que ni la reina ni su hijo ostentaban la condición de santos que le había sido reconocida a Fernando III. Las cajas fueron abiertas entonces, dejándonos testimonio de ello Ortiz de Zúñiga. La referencia a la reina es breve, repitiéndose la descripción de la clavazón dorada en el exterior de la urna, y en el interior la pulsera negra de perlas, junto con unos guantes de punto de seda morada y oro muy destruidos (ibid., p. 424).

47 M. GÓMEZ MORENO, “Preseas reales sevillanas”, Archivo Hispalense, IX/27-32 (1948), pp. 191-204. 
campaña fotográfica cuyas imágenes son el único testimonio que hoy tenemos de los objetos que los componían. También aporta datos interesantes, sobre todo en los casos de Beatriz y Alfonso X, el doctor Juan Delgado Roig ${ }^{48}$. El cuerpo de la reina, que se hallaba en muy buen estado, estaba cubierto por ropas muy ricas. Llevaba camisa de lienzo fino, túnica muy larga de seda blanca árabe, con hilos rojos y dorados. Los temas decorativos son espirales conteniendo flores, y una franja en el borde de escritura cúfica con la palabra alyemen, que significa la felicidad. La pulsera mencionada en los relatos anteriores ya no se conservaba, aunque fueron halladas algunas cuentas sueltas en el interior de la caja. Del adorno del pelo solamente se conservaban algunos retazos de tela fina y alfileres de cobre. Fueron hallados también los restos de una flor y un pájaro ${ }^{49}$.

Resulta de gran interés la almohada o cojín de la reina, con doble funda, la primera con decoración de cuadrilóbulos con animales en su interior, y otra más rica al exterior con temas cristianos y orientales (Fig. 3).

Con esta funda exterior, y siguiendo el estudio de Gómez Moreno, se interrumpe el arabismo que veníamos observando en las telas ricas, para dar así paso a un arte completamente cristiano, aunque impregnado de un cierto orientalismo. Estas observaciones llevaron a Gómez Moreno a preguntarse, ya en el año 1948, si esta funda de almohada no habría sido traída de Alemania por la propia reina cuando vino a Castilla para contraer matrimonio con Fernando III ${ }^{50}$. Por uno de los lados, esta segunda funda presenta una cenefa exterior con formas hexagonales que contienen cuatro animales alternados: dragón, águila, león y grifo. La otra cara sería la principal, con representación de escenas de temática cristiana para unos y galante o cortesana para otros $^{51}$. Se disponen las escenas en dos registros divididos en dos arcos con columnilla central. El registro superior está muy dañado, y solo se conserva una de las escenas, que se compone de dos figuras en el acto de abrazarse. Según María Jesús Sanz, siguiendo lo testimoniado por Gómez Moreno, se trataría de una figura masculina y otra femenina ${ }^{52}$. Si tenemos por acertada esta atribución, no tendría cabida la identificación de esta escena con la Visitación, aunque sí podría tratarse iconográficamente de una representación del Abrazo en la Puerta Dorada.

En mejor estado de conservación se encontraba el registro inferior, ofreciéndonos la representación de una figura bajo cada arco (Fig. 4). Una sería una figura femenina que sostiene un objeto en la mano y otra masculina que porta una flor y tiene un ave a sus pies. En esta escena se ha querido ver una Anunciación ${ }^{53}$. Esta identificación iconográfica resulta de difícil aceptación, ya que se nos muestra la figura de un án-

48 J. DELGADO ROIG, "Examen médico legal de unos restos históricos. Los cadáveres de Alfonso X el Sabio y de doña Beatriz de Suabia”, Archivo Hispalense, IX/27-32 (1948), pp. 135-153.

49 M.J. SANZ, op. cit., 2000, p. 429.

50 M. GÓMEZ MORENO, op. cit. (1948) p. 202.

51 Gómez Moreno reproduce ambas hipótesis, apuntando que la de que se tratara de escenas galantes es poco verosímil (ibid.)

52 M.J. SANZ, op. cit., 2000, p. 430.

53 M. GÓMEZ MORENO, op. cit. (1948), p. 202. 
gel carente de alas, la paloma del Espíritu Santo se encuentra posada en el suelo ${ }^{54}$, y no en vuelo como es habitual en este tipo de representaciones, y por último no hay ejemplos de una escena de Anunciación en la que la Virgen ofrezca un objeto, a modo de presente, al ángel anunciante. Parece aún más improbable esta atribución si comparamos la configuración de la escena de la almohada de doña Beatriz con la representación iconográfica de la Anunciación que aparece en las Tablas Alfonsíes ${ }^{55}$.



Fig. 4. Detalle del registro inferior del anverso del cojín de Beatriz de Suabia [M.J. SANZ, op. cit., 2000, p. 431].

En nuestra opinión, estas escenas tendrían una temática galante, más acorde con fuentes trovadorescas que religiosas. Así, consideramos que lo representado en la almohada de doña Beatriz podría relacionarse con una escena de ofrenda floral con carácter nupcial, como la representada en el fresco del Palazzo Finco de Bassano del Grappa (Fig. 5), territorio perteneciente a los dominios de Ezzelino da Romano, uno de los principales aliados de Federico II en el Norte de Italia y que incluso contrajo nupcias con una de las hijas del emperador: Selvaggia. Sabemos también de la existencia de contactos diplomáticos entre Ezzelino da Romano y Alfonso $\mathrm{X}^{56}$.

54 Si nos fijamos en el ave representada a los pies de la figura masculina, comprobamos que se podría corresponder más con la representación de un ave de caza extraída del tratado de cetrería De Arte Venandi cum Avibus que con una paloma.

55 M.J. SANZ, op. cit., 2000, p. 431.

56 M. GONZÁLEZ JIMÉNEZ, op. cit., 2004, p. 119. Para más información sobre este personaje vid. P. GRILLO, "Ezzelino III da Romano: un magnifico tiranno", Medioevo, 11, noviembre (2001), pp. 83-87. 
Este fresco fue sacado a la luz en el año 1993, y fue estudiado en primera instancia por Maria Elisa Avagnina, dándolo a conocer con motivo de una exposición dedicada a la figura de Federico II en Bari en el año $1995^{57}$. Esta escena de vida cortesana nos muestra cómo una figura masculina coronada y entronizada, identificada con Federico II, ofrece una flor a una figura femenina también coronada y entronizada que sostiene en su mano izquierda enguantada un ave, habiéndose identificado esta figura con Isabel de Inglaterra, tercera esposa de Federico II. La realización de este fresco se ubica cronológicamente del 1238 en adelante, y se cree que pudo llevarse a cabo con motivo de una visita del emperador a Bassano, que jamás llegó a producirse, prevista para principios del año $1239^{58}$.

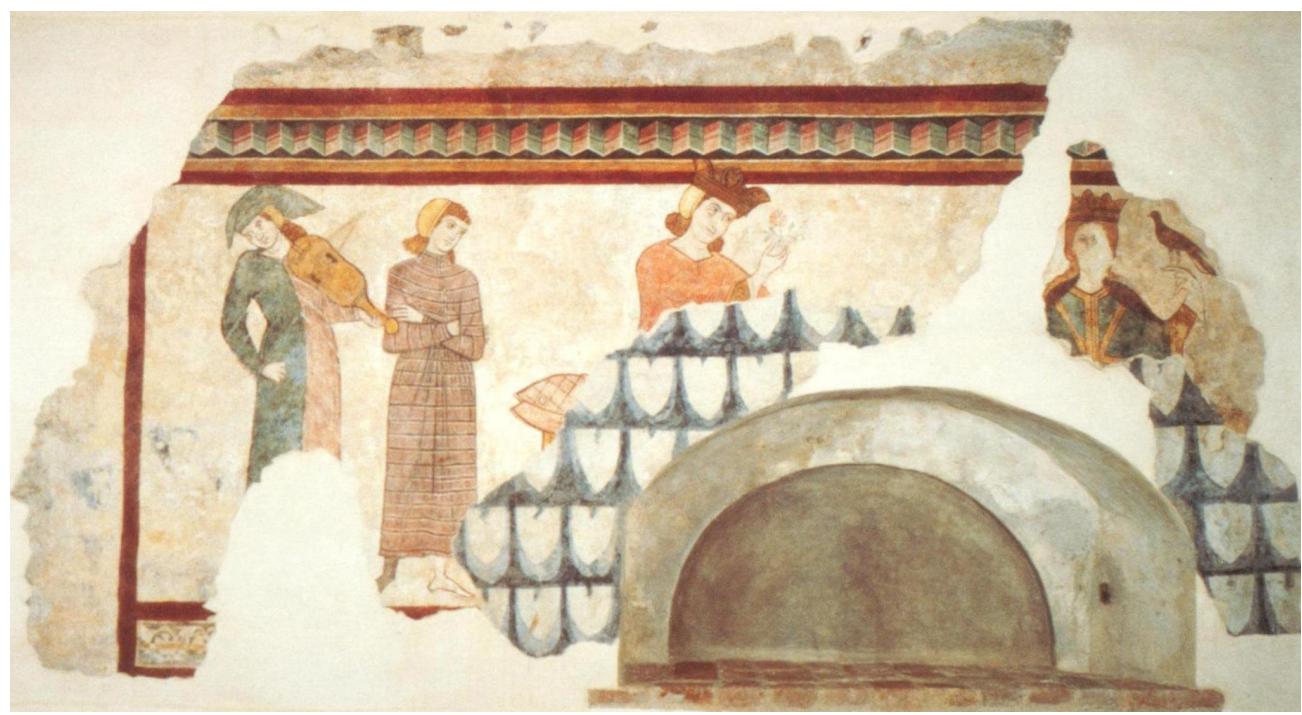

Fig. 5. Fresco del Palazzo Finco, Bassano del Grappa, Italia, c. 1238 [M.E. AVAGNINA, op. cit., 1998, p. 149].

Se incorporan otras dos figuras en la composición. La primera de ellas se identifica con un trovador, que toca un instrumento de cuerda. Su rica vestimenta parece denotar que se trata de un trovador de alto rango, y ha sido puesto en relación por Maria Luisa Meneghetti con otras representaciones de trovadores en distintos manuscritos ${ }^{59}$.

57 M.E. AVAGNINA, "Un inedito affresco di soggetto cortese a Bassano del Grappa: Federico II e la corte dei da Romano", M.S. CALÒ MARIANI y R. CASSANO (coords.), Federico II. Immagine e potere, Bari, 1995, pp. 105-111. Vid. también M.E. AVAGNINA, “L'incontro con la Marca e con Ezzelino. L'eco dell'imperatore: due cicli pittorici federiciani nel territorio della Marca Veronese e Trevigiana", C. BERTELLI, y G. MARCADELLA (coords.), Ezzelini. Signori della Marca nel cuore dell'Impero di Federico II, Bassano del Grappa, 1998, pp. 147-155.

58 Ibid., p. 107.

59 M.L. MENEGHETTI, "Federico II e la poesia trobadorica alla luce di un nuovo reperto iconografico", C.D. FONSECA, y R. CROTTI (eds.), Federico II e le civiltà comunali nell'Italia del Nord, Roma, 1999, pp. 507-523. 
En la segunda figura se ha querido ver la representación de distintas personalidades, entre las que querríamos destacar la de Pier della Vigna ${ }^{60}$, jurista del entorno más cercano de Federico II que fue el encargado de desplazarse a Inglaterra para realizar los trámites necesarios para el enlace del emperador con Isabel, hermana de Enrique III de Inglaterra ${ }^{61}$.

Parece ser que este fresco intentaba celebrar, mediante una ofrenda floral, los desposorios de Federico II con Isabel de Inglaterra. Nos encontramos pues, ante una temática nupcial, que quizá pudiéramos trasponer, desde un punto de vista iconográfico, a la escena del cojín del ajuar funerario de la reina Beatriz de Suabia. De este modo, si retomamos el interrogante abierto por Gómez Moreno en el año 1948 sobre la posibilidad de que la funda del cojín fuera traída desde Alemania por Beatriz para su matrimonio con Fernando III, podemos atisbar la probabilidad de que dicho cojín formara parte del ajuar nupcial de Beatriz, al igual que formaba parte de él la corona de las águilas, corona nupcial de doña Beatriz que lució la Virgen de los Reyes hasta abril de 1873, cuando se produjo su desaparición ${ }^{62}$.

\section{El simulacro de Beatriz de Suabia}

Por último, y haciendo una recopilación de los numerosos datos ofrecidos en las páginas anteriores, intentaremos realizar una propuesta iconográfica para el simulacro de la reina Beatriz que se encontraba en la Capilla de los Reyes de Sevilla junto a las representaciones de Fernando III y Alfonso X.

Una vez más nos enfrentamos a una ausencia de noticias con respecto a la representación de la reina, por lo que deberemos establecer paralelismos con las noticias que nos han llegado de los otros dos simulacros para poder construir una hipótesis.

Nos remontaremos para ello a la descripción más antigua y rica que poseemos de la Capilla de los Reyes de la Catedral de Sevilla. Se trata del relato de Hernando Pérez de Guzmán, datado en 1345, y del que reproducimos el fragmento referido a la descripción de los simulacros:

"E está el buen rey don Fernando en su siella asentado. E está la reina doña Beatriz de la otra parte asentada en su siella. E son las siellas cubiertas de plata. E están todos tres vestidos de mantos, pelotes, e sayas de baldoque, e dicen que tienen vestidos su pannos, camisas e pannos menores. E tiene el rey don Alfonso una corona de oro con muchas piedras preciosas, e tiene en la mano una piértega de plata con una paloma, e

\footnotetext{
60 A parte de su papel como jurista, destaca como compositor de distintas epístolas, interesándonos para este estudio una en particular que viene precedida por el epígrafe "Petrus de Vinea imperatrici, describens virtutes rosae et violae, diffiniens quae sit praeponenda" refiriéndose a la emperatriz Isabel de Inglaterra y en la que establece una comparación entre las virtudes de la rosa y la viola (M.L. MENEGHETTI, op. cit., 1999, pp. 516-517).

61 F. RENDA, op. cit., 2012, p. 131.

62 Vid. T. LAGUNA PAÚL, "El Imperio y la Corona de Castilla. La visita a la Capilla de los Reyes de Sevilla en 1500”, C. COSMEN ALONSO, M.V. HERRÁEZ ORTEGA, y M. PELLÓN GÓMEZ-CALCERRADA (coords.), El intercambio artístico entre los Reinos Hispanos y las Cortes Europeas en la Baja Edad Media, León, 2000, pp. 226 y ss.
} 
en la mano izquierda una mançana de oro con una cruz. E está enmedio el rey don Fernando su padre, asentado en su siella de plata. E tiene en la cabeza el rey don Fernando una corona de oro de tales piedras preciosas, como las sobredichas, e tiene en la mano derecha una espada, que dicen que es de gran virtud, con la cual ganó a Sevilla, la cual espada tiene por atrás un rubí que es tamaño como un guebo, e en la cruz de la espada una esmeralda muy verde. E los que quieren guarecer del mal que tienen, besan en aquella espada, e son luego guaridos: tiene en la mano izquierda la vaina del espada, en que están engastonadas muchas piedras preciosas. E está a cabo la reina doña Beatriz su mujer, vestida de pannos, de turques, e tiene en la cabeza una corona de oro en que están muchas piedras preciosas, e parece la más fermosa mujer del mundo"63.

Tal y como habíamos avanzado, esta fuente ofrece una escrupulosa descripción de los simulacros de Fernando III y Alfonso X, mientras que a Beatriz dedica escasas líneas.

Podemos comprobar cómo los atributos con los que se representa a Fernando III y a Alfonso X son los mismos que podemos encontrar en sus ajuares funerarios ${ }^{64}$. Quizá esto nos debería llevar a pensar que, en el caso de la reina, nos encontraríamos ante la misma situación. Así pues, si volvemos a retomar lo dicho anteriormente sobre el ajuar de Beatriz, los objetos hallados en su caja fueron una pulsera de cuentas, el esqueleto de un pájaro y los restos una flor. Con estos elementos, podríamos proponer una representación de la reina Beatriz muy similar a la de la emperatriz Isabel de Inglaterra en los frescos del Palazzo Finco de Bassano del Grappa: una figura en trono, coronada, sosteniendo un ave en una mano y una flor en otra.

\section{Conclusiones}

Con todo lo expuesto, consideramos que es necesario realizar una puesta en valor del papel que desempeñó doña Beatriz en el proyecto de la Capilla de los Reyes de la Catedral de Sevilla, revalorizando así el interés por su ajuar y por su simulacro. Por todas las noticias históricas que hemos aportado, nos parece que la realización del simulacro de la reina se deba enmarcar dentro del proyecto de exaltación imperial alfonsí, y no dentro de las aportaciones posteriores de Sancho IV.

Por lo que respecta al ajuar, consideramos factible que el cojín de la reina Beatriz fuera parte del ajuar nupcial, de igual modo que lo fue la corona de las águilas, que ella misma trajo desde Alemania en el año 1219; mientras que para la propuesta iconográfica será necesario seguir profundizando en su investigación, habiendo realizado en esta ocasión una propuesta basada en paralelismos con obras de la órbita de los Staufen, por un lado, y por el otro, estableciendo una comparación con las noticias llegadas a nosotros de los simulacros de Fernando III y Alfonso X

63 A. MARCOS BURRIEL, "Memoria o noticia del estado y forma que tenía la capilla de nuestra señora de los Reyes, antes que se labrase la nueva", Memorias para la vida del santo rey Don Fernando III, dadas a luz con apéndices y otras ilustraciones por Miguel de Manuel Rodríguez, Madrid, 1800 (tomado de L. FERNÁNDEZ FERNÁNDEZ, op. cit., 2012, pp. 144 y 145, nota 27).

64 Vid. M.J. SANZ, op. cit., 2000, pp. 419-447. 
Una vez más, se pone de manifiesto la amplia red de relaciones políticas, diplomáticas, familiares y artísticas que existieron entre el Reino de Castilla y el Imperio en el s. XIII. Desafortunadamente, las imágenes de las cuales disponemos en la actualidad para este estudio son escasas y de una calidad muy limitada, por lo que sería conveniente para enriquecer esta investigación tener la oportunidad de acceder a reproducciones gráficas de mayor calidad, empresa que solo sería posible con una nueva apertura de las cajas. 